\title{
Student Law Office Conference: A Platform for Student Engagement with Clinical Legal Education?
}

Mark Lynn

\section{Introduction}

I was one of a group of students from Northumbria University who organised the first student conference on clinical legal education on Saturday 4th December 2004. ${ }^{1}$ This short article is intended to explain why we thought such a conference was necessary and whether it was worthwhile.

\section{Why a student conference on clinical legal education?}

Clinical legal education has been established in other legal jurisdictions for decades and is seen as essential in providing the aspiring lawyer with pre-practice experience, yet it is still a relatively recent development in the United Kingdom. It is currently one of the fastest growth areas with increasing numbers of law schools establishing law clinics. However, there has been relatively little input from students regarding the nature of clinical legal education or the costs or benefits it brings.

Northumbria students spend a great deal of time in the Student Law Office, through clinical modules at Northumbria, and constantly reflect on their personal and professional development. Yet relatively little time is spent considering the way our clinical education is structured and delivered and what its aims and objectives should be. We saw the conference as an ideal opportunity to explore these wider issues and, more importantly, to involve students and staff from other institutions in this dialogue. The conference provided a forum for the exchange of ideas and information and provoked debate about the future of clinical legal education. The objective of

1 The event was kindly sponsored by Ben Hoare Bell solicitors of Sunderland. 
the conference was to obtain the views of different clinics and promote this type of legal education throughout the country.

\section{The Conference proceedings}

The conference was opened by Rebecca Barnes of the Solicitors Pro Bono Group and Professor Richard Grimes of the College of Law. Rebecca addressed the relationship between clinical legal education and lawyers' commitment to the principle of pro bono. Richard summarised some of his recent research into models of clinical legal education in the United Kingdom.

This was followed by a plenary session called 'Learning from each other' with a number of short presentations from visiting departments who shared the work of their clinics. Following this, there was a panel discussion on clinical experience and career opportunities with former students who are now in practice and employers who had experienced clinical legal education. This involved discussions of whether the work which students had encountered in their law clinics had been of a benefit to them in practice.

After lunch the conference split into workshops to discuss the dilemmas of working for real people. This workshop was designed by students from the committee and included real dilemmas encountered by students working in the Student Law Office, with due regard to confidentiality issues. The aim of these sessions was to provoke debate about the ethical, moral and practical dilemmas that students face in legal clinics as a result of working for real people. After discussing a number of issues in the various workshop groups, everyone in their group attempted to reach a consensus on two important issues to report back to the whole conference in the next session: (i) Clinics should only work for those who cannot afford a lawyer (ii) Clinics should only work for those who have a deserving case. Each group's feedback was then discussed before the whole conference and a number of ideas were exchanged.

After a mid-afternoon break, the day finished with a session grandly entitled 'The Utopian Clinic' whereby everyone had the opportunity to vote for their ideal clinic using "Who wants to be a millionaire" technology. During the course of this plenary a number of questions were put to the audience. For example: "Should clinical legal education be compulsory?" "Should clinics combine campaigning activity alongside case work?" Or even: "should students be paid for working in law clinics?" There was a resounding 'YES' for the latter!

\section{Themes emerging from the conference discussions}

The conference proved to be a huge success. Throughout the day it became very apparent that the amount of law clinics in this country was on the increase. During the workshop 'Learning from each other' everyone gained a deep insight into how far clinical legal education in this country has come. Rebecca Barnes from the Solicitors Pro-Bono Group made the point that when she studied Law there was no such thing as pro-bono and that she only gained experience of this when she began her training. Pro-bono is very important and should be promoted as it provides the chance to help people and solve the imbalance that exists in the law. Richard Grimes has done much research in this area and has found that there has been a steady increase in the amount of law clinics, which are being set up. He emphasised how important this type of education is by stating "Clinical legal education is all about studying the law through exposure to real or realistic case 
work with structured reflection", thus giving students the opportunity to think through what they have done. Only recently, Queen Mary University in London became the latest legal education provider to launch a pro-bono group, which shows that clinical legal education is on the increase. The group has already secured placements for Queen Mary students with Clifford Chance in its Canning Town project and with Allen \& Overy with its new twinning project.

As briefly mentioned earlier, the Conference involved a number of short presentations from visiting departments which included students and academics from BPP, Kent, Sheffield Hallam, De Montford, Bristol and Northumbria. This workshop enabled everyone to see how each University's law clinics worked and to assess the differences between them.

The workshop began with James Heward from BPP who is working at a legal advice centre in London, which only started full time operations in clinical work in October 2004. He explained that the advice centre initially learnt from a pilot scheme and that the attending students at the law clinic complete work with the help of a supervisor, similar to that of Northumbria (but the clinic at BPP remains voluntary and does not count towards assessment, unlike Northumbria). Such an idea was initially considered in October 2003 and they subsequently formed a committee to discuss such a possibility. Originally, they felt that it was very important to consider which areas of law they should advise on, taking into account both resources and the needs of the local community. Other issues to be considered included both recruitment and promotion. From his own experiences, he felt that the best route in establishing a clinic was to consider promotion at an early stage, visit conferences on clinical legal education and obtain feedback to assess how the clinic is operating. The law clinic at BPP focuses on housing and employment law, but they are also looking to expand into other areas.

We then heard from Rhona Sharlett from De Montford University who explained that their law clinic has been in operation for the past 15 years. Their law clinic does not advise the general public but instead, focuses on student's related problems. Undergraduates staff the clinic and there are four supervisors who help students with their various legal problems which they encounter. Due to the high profile that clinical legal education is receiving, the University has begun to run a recognised module, which teaches students about ethics, research and advocacy skills. However, De Montford have experienced a few problems recently when Leicester Council closed down the local advice centres, which subsequently meant that there was a surge of referrals to the University law clinic. This illustrates the potential problem of law clinics being seen as a cheaper alternative to properly funded state legal services.

Adam Wilson from Sheffield Hallam's University explained that their clinic is made up of both second and third year law students who deal with work from students and members of staff. The areas of expertise are restricted at Sheffield Hallam; however, they run cases in a similar way to that of Northumbria. The law clinic deals with about 35 cases a year, to enable students to concentrate on reflection. The type of work which they deal with includes personal injury, criminal law, contract, housing and consumer protection. The clinic operates in a similar way to Northumbria University's law clinic in that there are firms consisting of six students with about two to three cases per firm. Their students must initially attend an induction course before commencing work in the clinic. This induction course focuses on interviewing, professional ethics and confidentiality. Students must also compile an experience evaluation form to demonstrate and reflect on how they could have improved on what they have done. 
The Conference was also joined by students from Bristol University, who have a law clinic which has been running for nine years. It is an undergraduate programme with about 120 student members. In setting up their clinic, they aimed not to detract from the legal profession but just to be a supplementary facility. They are primarily a community service. Their law clinic recruits people through an application process, which has 30-40 places available. The new members then receive a training programme and new recruits work initially with more experienced advisors.

Two students from Northumbria University, Chris Simmons and Paul Roberts, explained the learning experience in the Student Law Office. They made the point that the Student Law Office is seen as an integral part of the course, which provides a good stepping-stone for the future. Students initially come into contact with the practical elements of the course in first and second year when students experience practical subjects such as litigation and evidence. Proceeding to third year, students concentrate on the Student Law Office on a hypothetical basis, which involves checking a theoretical conflict register and having a simulated interview with an actress. Students are also expected to attend workshops throughout the year whereby they have to conduct research into the relevant areas of law with regards the information obtained from the interview. This experience is intended to give students an idea of what is to be expected in fourth year. In fourth year, students are given their own case files and expected to follow them through the various stages, from the initial interview, to the follow-up advice interview, to representing the client at a court or tribunal if needs be. The benefits of the Student Law Office are that students gain a better understanding of how the law relates to real problems and how to apply this in a practical sense. The law clinic specialises in a number of areas including employment law, housing law, general civil litigation, criminal appeals and welfare benefits, now taking on about 500 cases a year. The University has very close links with local solicitor firms such as Ben Hoare Bell and Eversheds, who seek to help students with their cases.

Kent University students work in an in-house representation clinic at the University, which has over 130 members. Their course contains a clinical option module thereby providing law students with the choice of whether to experience clinical work. At Kent, the students fill numerous roles. For example, if first year law students wish to gain an insight as to how the clinic works, they can apply to be receptionists in the clinic, thus providing them with a feel of the working environment. The cases are dealt with on a 'first come, first served' basis, and they are not means tested. However, they have a general policy of only representing those people who can not afford legal advice. They have taken on 77 cases this term in areas such as employment, consumer protection, housing, immigration and family law. Besides working on individual casework, the students also work on behalf of community groups and carry out legal research and lobbying. The students recently acted for two Afghan youths who were due to be deported. The students gained publicity in the news and subsequently liaised with the Home Office whereby an agreement was reached, and the youths were allowed to stay. Such a case proves what a 'powerful educational tool' clinical legal education is.

Finally, we heard from Martin Wilson, a student from Northumbria University, who won a scholarship from Irwin Mitchell, and was given the opportunity to work in Springvale Monash Legal Service (SMLS) in Melbourne Australia, for one month. He explained the type of work he experienced over there and attempted to make a comparison with clinical legal education in England and Wales. SMLS aims at providing a high turnover of advice to the local community and is required to take on more in-depth cases than English clinics requiring more detailed research. 
He served to make the point that there are numerous similar University run schemes around Australia as they see work undertaken by student run law offices as strategic in delivering legal services to the public and as a result, they appear to be much more involved in the funding of certain aspects of the schemes than occurs in England and Wales. Students in Australia are involved in a varied range of legal problems across vast areas of law. However, he made the point that law clinics in the UK seek to serve a very different legal need, as drop in advice centres such as the Citizens Advice Bureau already exist in the England and Wales, and therefore law clinics are not expected to provide such a service.

\section{Did the conference succeed?}

Overall, I think that the day provided an excellent platform for student involvement and debate about their clinics. It enabled us to learn from each other's experiences and see how the various clinics differ from one another. We explored wider issues such as the scope and nature of clinical legal education and how the clinics are structured and delivered. One of the major benefits of having academics and students together was that it emphasised that clinical legal education is a partnership and allows us to learn from each other rather than the hierarchical approach that is typical of most learning. It also provided the enthusiasm for another conference next year. An issue that was missing from this conference was the perspective of the client who is advised or represented by the students. How do they feel and are their interests properly considered by clinics that have education as their main objective? Perhaps this is one theme that could be developed at the next conference.

Conferences like this one help us students think more critically and creatively about why we are doing what we do. It helps us see clinical work not just as an obligation or something attractive for our CVs but as part of what makes us understand the law and helps us become more rounded people. It should also make our lecturers see that we have a lot to offer in terms of the future of clinical programmes but this remains to be seen! 